\title{
EVALUATION OF EFFECTIVE FACTORS ON CUSTOMER DECISION-MAKING PROCESS IN THE ONLINE ENVIRONMENT
}

\author{
Mohammad Takhire $^{1}$ and M.R. Taghizadeh Joorshari (Corresponding Author) ${ }^{2}$ \\ ${ }^{1}$ M.A of Industrial Engineering, Rahbord Shomal University, Rasht, Iran \\ Department of Business Administration, Rasht Branch, Islamic Azad University, Rasht, \\ Iran
}

\begin{abstract}
The key effect of the development of online shops not only shifted the method businesses work, it also changed the manner costumer's behaviour. The aim of this study is to assess the impact of social identity, Electronic word-of-mouth (EWOM), perceived risks, and trust and purchase intentions affecting customer decision \-making process in online shops. A research model is illustrated, using technology acceptance model (TAM) as scientific base, to describe the relations of these variables that affect purchase intention and finally leading to actual purchase. With the use of structured questionnaires on 655 respondents via emails, this research examines online shop site namely, digikala. The analysis explains that purchase intention and purchase behaviour, EWOM and trust in online shops and trust to purchase intention have positive relations. As well as, perceived risk with trust and purchase intentions have negative relations. Further, relation between social identity and trust not confirmed.
\end{abstract}

\section{KEYWORDS}

Purchase intention, word-of-mouth, perceived risk, trust, Online shop.

\section{INTRODUCTION}

With the development of the Internet, electronic commerce has become a main channel for business (Ho, 2014). With the utilization of online shops significantly, they have increasingly become a complete section of costumers' daily lives. For the seller, the business opportunities are vital dependent on costumers' receptiveness of online shops as trustful retailers. In fact, with growing predominance of sell sites, businesses would be interested how online shops can be part of the strategy to reach out to potential customers. In the sphere of consumer behavior, the effects of online shops should be valuable to marketers, mainly in the manner, consumer's research and assess information, the way purchase intentions are found and finally leading to actual purchase behavior. To suitable usage of the opportunities (and also avoid dangers) provided by these online shops, we need to find out why consumers are attracted to them and how they influence their purchasing behavior. In technology acceptance model (TAM), provided the logical sequence of events and sources of influences exert on consumers during the decision making process and buying. Through online shops, consumers can show their enthusiasm in their favorite brands. Product survey and product-related matters and answers generated by consumers are quickly accessible to everybody, anyplace with the use of online shops. This form of costumer articulation is well-known as electronic word-of-mouth (EWOM). In other words, consumers talked about services and products because they sense that they are doing others an assistance by highlighting the pros and cons. More mainly, many prior studies find out that consumers pay attention to word-of-mouth communications because of "confidence and trust" 
International Journal of Managing Public Sector Information and Communication Technologies (IJMPICT), Vol. 6, No. 3, September 2015

(Brown et al., 2010; Evans and Bretton 2010). It is of high interest to discover why peoples trust the broad measure of EWOM that are floating in these online shops and how they change costumer decision making in this online shops. The online shops are recognized as virtual communities where peoples use the internet to deal and interact. As these online shops are essentially online communities, the element of social identity is crucial for consumer membership and participation.

Teo \& Yeong recognized that as peoples shifted their decision making online, the cognitive behavioral and social base of the decision-making will transform in procedures that are as yet tendentiously understood. With online shops growing dominance in our daily purchases, customers can modify related information about services and products quickly, therefore reducing search time, and information seek cost and the amount of perceived risk. Many previous studies found great evidence of WOM impact over purchase decisions (Goyette et al., 2010). Also, the former researches focused on niche area in addressing consumer behavior in these online shops, such as social influence (Zeng et al., 2009) and trust and perceived risk (Kim et al., 2008) but do not investigate these variables in entirety.

Hence, the objective of the study is to examine the antecedents of online purchase intention by integrating social identity, EWOM, perceived risks and trust into TAM model.

\section{THEORETICAL BACKGROUND}

\subsection{Consumer Behavior View}

Consumer behavior is a broad sphere of research about the decision making processes that a consumer make at the time of making a purchase. Consumer decision-making process involves a very wide variety of personal and situational variables (Teo and Yeong, 2003). In the consumer behavior literature, there are numerous models on consumer decision making process. These models illustrate the different stages that go through the mind of the consumer from the initial ignorance of a particular brand or product or service to the actual purchasing behavior (Hansen, 2005). Often, three theories, namely Theory of Planned Behavior, Consumer Decision Making Process Model and Technology Acceptance Model, are examined to provide a fundamental understanding in consumer behavior. In this paper Theory of Acceptance Model (TAM) was used. This theory helped to shape the formation of the conceptual model of this paper and is thus presented here.

\subsubsection{Technology Acceptance Model (TAM)}

TAM was introduced by Davis (1986) to describe the usage behavior of new technologies (Rauniar et al., 2014). The Technology Acceptance Model is a special conformity of Theory of Reasoned Action for IT usage. Similar to Theory of Reasoned Action and Theory of Planned Behavior, behavior is defined by the intention to perform the behavior. In this study, the conceptual model draws that intention to purchase leads to actual purchase. The underlying assumption of Technology Acceptance Model assumes that the behavior is volitional. However, Technology Acceptance Model does not include behavioral control construct, which means that behavior is directly at the discretion of oneself. In other words, this model does not explain cases where consumers are not able to perform transactions even though there is an intention to do so. For example, consumers do not have sufficient money or credit card for purchases (Loh, 2011). 


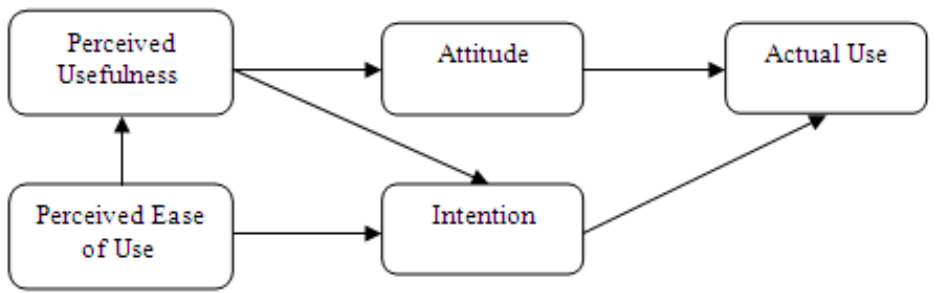

Figure 1: Technology acceptance model, TAM. Source: Davis (1986).

\section{VARIABLES AND HYPOTHESES}

\subsection{Purchase Intention}

Drawing from Theory of Acceptance Model in the preceding section, consumer intentions to engage in online transactions are significant predictor of consumer actual participation in ecommerce transaction (Kim et al., 2008). The relationship between intention and actual behavior is driven by the assumption that human beings attempts to make rational decisions from the available information to them. Therefore, an individual's intention to perform (or not to) a behavior is a main determinant of the individuals' actual behavior. Based on this intentionbehavior relationship, this study predicts that a consumer's intention to purchase from the online shops sites is a predictor of the consumer's actual purchase behavior. The assumption here is that consumers make planned purchases. So:

H1: The consumer's intention to purchase through online shops, positive effects on the decision to actual purchase.

\subsection{Word of Mouth Communication}

One of the earliest study on WOM, Arndt (1967) recognized WOM as oral, person-to-person communications regarding a shop, brand, product or service between a receiver and a communicator who is perceived as independent of any economical effects. Kozinets et al. (2009) defined WOM marketing as the intentional influences of consumer-to- consumer by professional marketing technique. We can describe word-of-mouth as costumers' interpersonal communication about products or services, and it is a commonplace that WOM plays a key role in influencing consumer attitudes, tendencies and behaviors (Kim et al., 2014).

Many researches have shown that WOM has major impact on consumer choice and postpurchase perceptions. In Figure 2, it illustrates the evolution of WOM theory.

Early Stage of WOM

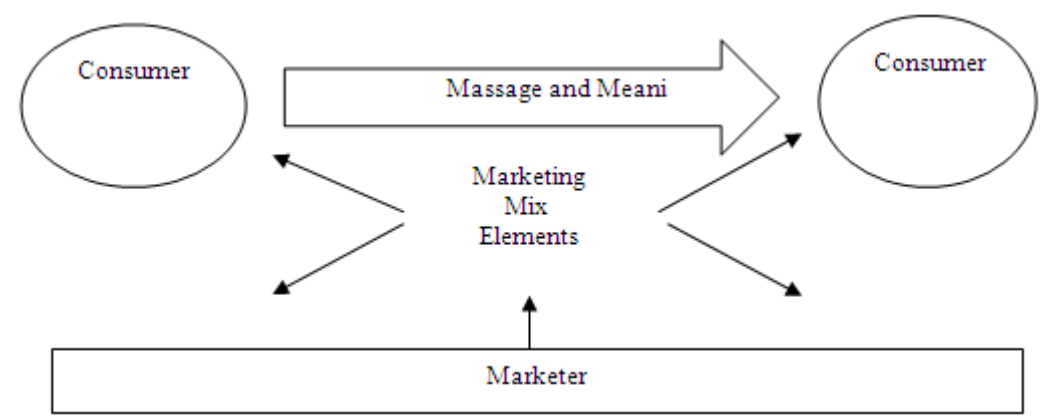


Second Stage of WOM

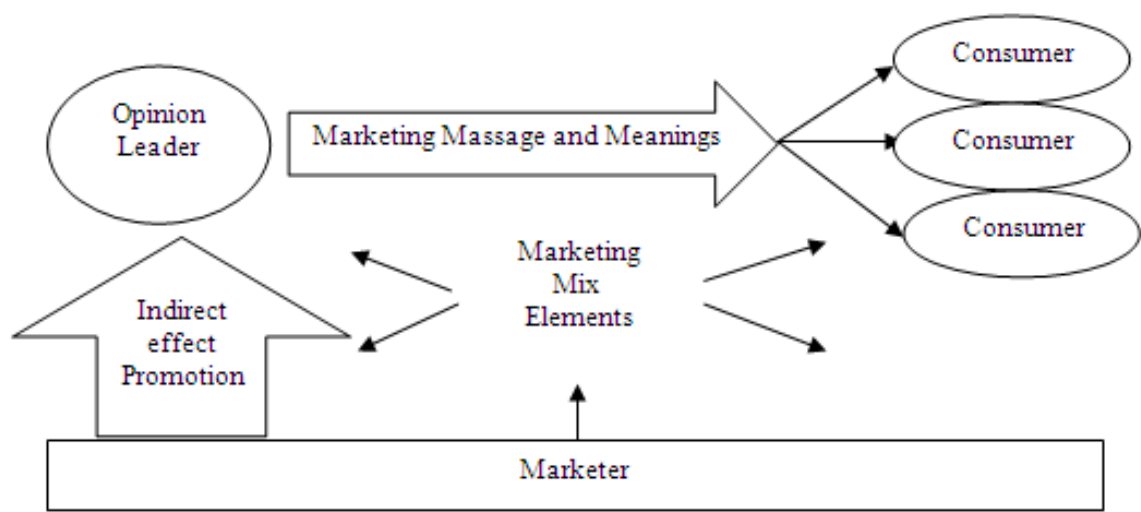

Third Stage of WOM

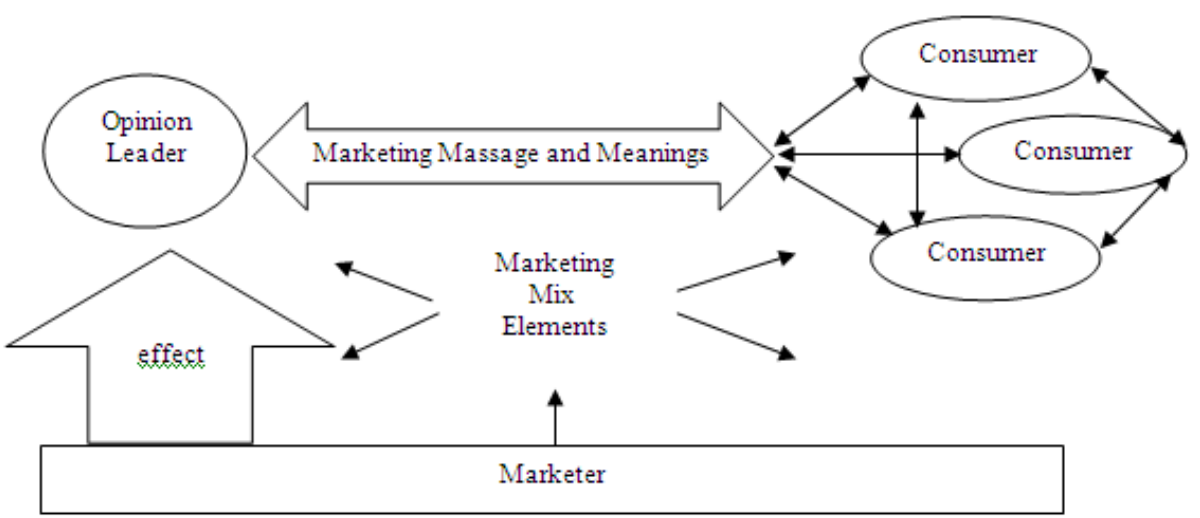

Figure 2: Evolution of WOM theory

(Adapted from Kozinet et al., 2009).

Early forms of WOM, are motivated by the desire to help others, to warn others about poor services and/or to communicate status. At this stage, WOM was commonly assumed to occur naturally among customers when marketers perform their jobs of developing market innovation, product promotions and advertising (Kozinet et al., 2009). The second step of WOM scientific development formed as marketing learning and experienced progressions, theories of WOM emphasized on the significance role of exclusively influential consumers in the process of WOM as said by Kozinet et al. (2009). These opinion leaders are targeted and influenced by marketers, which in turn will recommend their friends about the particular product. The third stage as defined by Kozinet et al. (2009) is the direct managing of WOM activity through targeted one-toone seeding and communication program. With the internet allowing unique new levels of management, effective growth and development of WOM marketing are ensued. In the context of online shops, WOM marketing is particularly prominent due to the nature of its communications capability in terms of reach and depth. However, with the vast amount of WOM generated in online networks, it is questionable how much trust consumers have on them. Despite fundamental similarities in purposes, there are several key differences between EWOM (Electronic Word-of-Mouth) and traditional WOM (Steffes and Burgee, 2008). Firstly, WOM involves face-to-face conversation while EWOM occurs over the internet where sender and receiver are separated by time and space. Next, EWOM harness the unlimited reach of internet to 
International Journal of Managing Public Sector Information and Communication Technologies (IJMPICT), Vol. 6, No. 3, September 2015

share opinion and experiences to the whole world while traditional WOM cannot do. Lastly, traditional WOM emanates from a known sender where the receiver is aware of his/her credibility. The nature of EWOM in most applications does not allow the receiver to judge the credibility and the message contents. It was found that consuming EWOM is strongly driven by utilitarian motives such as getting purchase or consumption-related advice while posting EWOM is largely attributed by social-psychological factors, identity and utilitarian motives (Hennig-Thurau et al., 2010).

The important element that is driving up word-of-mouth communications is "trust" (Evans and Bretton, 2010). Consumers attend to WOM since it is perceived as valid, reliable and created by individuals having no benefit in purchasing a product (Brown et al., 2010). Individual's perceptions of WOM accuracy will depend on the opinion that the sender's ideas and suggestions are fair. As such, trust between friends and colleagues or, the social relations between them help to determine trustworthiness of WOM communications during purchase decisions process. Therefore, in online environment like, trust is expected to be a significant factor in consuming EWOM. We therefore propose the following hypothesis:

$\mathrm{H} 2$ : EWOM is positively related to trust in online shops.

\subsection{Social Identity}

Identification with a social group is a psychological state very different from merely being specified as falling into one social category and has significant self-evaluative outcomes. In this research, online shops are viewed as platforms to provide for social identification process. In addition, social influence can manipulate consumer decision making, Witt (1969) found that group effect and group awareness of member choice are significantly related to similarity of brand choice within group. However, the influence of social identity affecting purchases in online shops has yet been extensively explored. Overall, Social identities can provide support in stressful situations (Frings and Albery, 2015). This paper hopes to prepare some empirical findings to suggest the influence of social identity in consumer decision-making process online shops. To explain why consumers participate actively in online communities, Bagozzi and Dholakia (2002) found that social identity motivates the participation in online interaction by enhancing 'we-intentions', i.e. people's commitment to participate in a joint action, and involve consent between the participants to engage in the collective action. They added that the membership, frequency and extent of participation are driven by volitional choices. In addition, Wasko and Faraj (2000) found that people participate in online community primarily out of community interest, generalized reciprocity and pro-social behavior. According to Shen et al. (2009), the major driving force of social identity is affective social presence, which is referred as the extent to which a user's emotional connection is aroused by the virtual social interaction with others. Lin (2010) study on online gaming communities find out that effective commitment and social norms are key influences to community loyalty behavior. Extending from these various researches, this study would like to investigate if the influence of social identity also exists and how they differs in online shops.

The fundamental purpose of social sites is to provide a platform for people to interact, the social and community purpose become a major part of its utility; hence the concept of social identity fits in. Through the participatory interactions with the group members, they formed strong relationship bondage and trust among them is developed. Trust is thought-out vital in business relations because it is a key factor of social capital (Kim et al., 2008). The degree of relation a community member has with the others in the social networks will influence upon the kinds of bonds and relationships that are built among the members (Quinton and HarridgeMarch, 2010). Online relationships can be just as strong and deep as off-line relationships. This 
International Journal of Managing Public Sector Information and Communication Technologies (IJMPICT), Vol. 6, No. 3, September 2015

is very much dependent on the level of trust they have. In the era of e-commerce, issues surrounding privacy and security made online audience skeptical of marketing or advertising. Moreover, virtual communities and social network sites which lack face-to-face contact, makes the element of trust seems more significant in online communications and interactions. Lin (2008) found that trust is important in conditions where lack of workable rules needs others to behave in a socially adoptable way. In other words, mistrust creates barriers in forming sustainable relationships and social function of these online communities (Lin, 2008). Thus, this study postulates that social identity forms a considerable component of building the element of trust during the consumer decision process. Therefore, H3: Social identity is positively related to trust.

\subsection{Perceived Risk}

A consumers' perceived risk is a major barrier for online costumers. The intangible and impersonal character of online shops and the implicit uncertainty of using the open global infrastructure for transactions have rendered risk an inevitable of e-commerce (Pavlou, 2003). According to Featherman and Pavlou (2003), perceived risk is described as "the potential for loss in the pursuit of a desired result of using an e-service" (Martins et al., 2014). In the consumer behavior and marketing literature, perceived risk is a vital concept and various types of risk have been identified (Kim et al., 2008; Pavlou, 2003). For example, Jacoby and Kaplan (1972) identified there are seven types of risk: performance, financial, physical, social, psychological, time and opportunity cost risk. Risk aversion usually leads to negative reactions to advertisement, marketing campaigns and promotions. Precisely due to the inherent nature of online shopping, consumer always experience some types of risk. The perceived risk can be so overwhelming compared to traditional mode of shopping, therefore inducing reluctance to purchase. During internet transaction, consumer has to provide personal information, address, phone number and credit card information. After providing the essential information, the consumer has to wait for days for goods to be delivered and then, transaction is completed. Thus, it is not surprising that consumers are attentive to risk in online transaction and such risk may directly influence their intention to purchase from the online retailer. In these unknown conditions, where costumers have to act, trust comes into play as a key solution for special problems of risks. Kim et al. (2008) argued that trust can alleviate the effect of risk on online purchases in situations where one must enter into risks but have no complete control over the outcome. It was considered that the impact of trust is mediated by risk on the purchase intention of consumers. Taking these findings into consideration, this paper endeavors to unveil the relationship between perceived risk and trust in online shops. In addition, perceived risk can also directly have a significant effect on intention to purchase. In other words, if the consumer deems that the associated risks of the online purchase outweigh the level of trust he or she has with the online retailer, she may reject patronage. The fear of associated risks such as privacy, monetary, and product risks can be so overwhelming that consumers rather choose not to buy at all(Kim et al., 2008). Therefore:

H4: Perceived risk negatively relates trust.

H5: Perceived risk negatively relates intention to purchase.

\subsection{Trust}

Trust is vital in exchange relations because it is the key element of social capital and it affects loyalty, firm performance, satisfaction, competitive advantage and other economic outcomes like transaction costs and search cost reductions. Though e-commerce gives a range of advantages that collectively have been shown to be important enough to attract massive interest, new research showed that a basic problem in e-commerce environment is trust (Yoon and Occena, 2015). In e-commerce context, most studies on trust focused on technological issues 
relating to security, privacy and other key aspects of trust (Kim et al., 2008). Since there are already many researches done on trust, many definitions of trust have evolved. In Ha and Perks (2005), it defined brand trust as an average consumer to rely on the ability of brand to perform its stated function. Plank et al. (1999) identified that costumer trust could have various referents: salesperson, service, product and the company and accordingly described trust as a general belief on the part of the buyer that the salesperson, product and the company will deliver its obligations as understood by the buyer. In this study, we focus trust on the internet retailers in online shops. As discussed earlier, trust is important during consumer decision making process. Trust is essential in order for meaningful interactions and information exchanges to occur, to undertake the risk of providing personal information and believing that the online retailers will deliver goods as promised. In order for consumers to develop the intention to purchase, first and foremost, consumers are expected to trust the online retailers in believing that they will deliver the promised action. In line with the arguments of Theory of Planned Behavior, this study views trust as an important behavioral attitude towards the intention to purchase in online shops. In the marketing perspectives, knowing the level of trust the consumers have is an important prerequisite for intentions to purchase to form. These intentions to purchase are important determinants of the successfulness of these businesses to penetrate new business arena in online shops (Loh, 2011). Therefore, this study explores if there is a direct relationship between trust and purchase intentions.

H6: A consumer's trust is positively affects the intention to purchase.

\section{RESEARCH MODEL}

The purpose of this research is to assess the effect of social identity, perceived risks, EWOM, trust and purchase intentions affecting costumer decision-making process in online shops. Figure 3 shows the conceptual model explaining the relationships of constructs in this study and how the constructs are expected to be related. However, this does not represent the complete list of factors that will affect consumer decision-making process in reality. Neither does this thesis seeks to test the robustness of this research model. The main objective of this study is to investigate the factors that are expected to be significantly more prominent in online environment, specifically in online shops. In the context of consumer decision-making process, it is reasonable to expect purchase intentions will lead to actual purchase behavior. In the conceptual model, trust is viewed as the behavioral belief that is central in guiding consumers during purchasing decision. Social identity and EWOM are exogenous variables affecting trusts. As the nature of online shops is to provide a platform for individuals to interact, the social and community purpose form an important part of its utility, where the concept of social identity fits in. Perceived risks are viewed as behavioral control affecting trusts and also directly affecting purchase intention. This is a significant and key character of this research model as it notices the role of behavioral controls that is straightly hindering purchase intentions, which is extracted from Theory of Planned Behavior. If there is excessive perceived risk, it is expected to deter the intention of purchase directly.

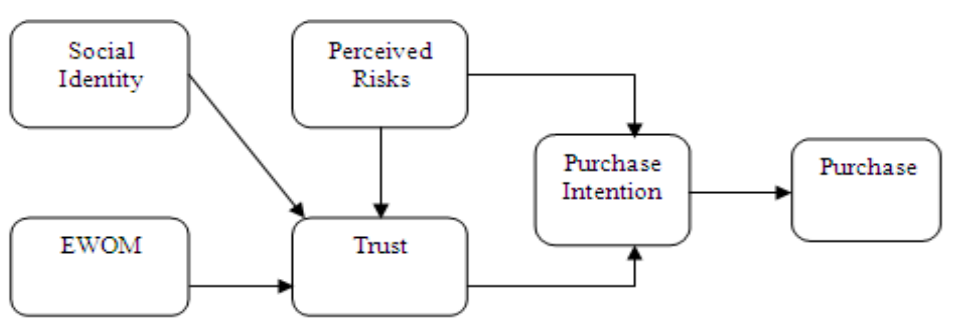

Figure 3: Research model. 


\section{RESEARCH METHODOLOGY}

This research, in terms of purpose is applied and the method of data collection is descriptive correlational and based on structural equation modeling (SEM) methodology. Theoretical foundations and background of research has been developed with using of library resources, information base and refer to the experts. The population of research is including customers of digikala online shop. After 3 weeks of data collection, 655 students used for analysis. In this study, to collect data and analyze the information was used the standard questionnaire. The questionnaire consists of 25 questions in 6 dimensions which and all the constructs are measured using multiple items gathered from the survey, using a five-point liket-type scale (from 1= Strongly Disagree to 5= Strongly Agree). For measuring the reliability of the tool of the study was used cronbach's alpha method. To estimate the reliability coefficient, first 30 questionnaires were distributed between the samples of population that cronbach's alpha coefficient of the dimensions researches presented in the table below:

Table 1: Reliability of research tool.

\begin{tabular}{|c|c|}
\hline Dimensions & Cronbach's Alpha \\
\hline Purchase & 0.88 \\
\hline Purchase Intention & 0.85 \\
\hline EWOM & 0.82 \\
\hline Social Identity & 0.77 \\
\hline Perceived Risks & 0.80 \\
\hline Trust & 0.79 \\
\hline
\end{tabular}

\section{ANALYSIS AND FINDINGS}

The descriptive statistics were analyzed using SPSS 17.0 for Windows. To test research hypothesis using LISREL 8.70.

\subsection{Profiles of the respondents}

Briefly, $40.0 \%$ of the respondents were female and $60.0 \%$ was male; $60.30 \%$ were aged between 20 and 30 years, and $26.71 \%$ were aged between 31 and 40 years; $61.83 \%$ bachelor student and $38.17 \%$ master or doctoral students. In relation to Internet use through devices, results show that, in general, respondents access the Internet, on the average, between 4 and $6 \mathrm{~h}$ a day.

Table 2: Complete demographic information of the survey respondents.

\begin{tabular}{|c|c|c|c|}
\hline Demographic characteristics & Frequency & Percentage \\
\hline Gender & Male & 410 & 60.0 \\
& Female & 245 & 40.0 \\
\hline \multirow{3}{*}{ Age } & $20-30$ & 395 & 60.30 \\
\cline { 3 - 4 } & $31-40$ & 175 & 26.71 \\
\cline { 3 - 4 } & Older than 40 & 85 & 12.99 \\
\hline Education & bachelor degree & 405 & 61.83 \\
\cline { 3 - 4 } & master or doctoral degree & 250 & 38.17 \\
\hline \multirow{3}{*}{ Internet use per day } & Less than 1 h a day & 103 & 15.70 \\
\cline { 3 - 4 } & Between 1 and 3 h a day & 223 & 34.00 \\
\cline { 3 - 4 } & Between 4 and 6 h a day & 151 & 23.10 \\
\cline { 3 - 4 } & Between 7 and 9 h a day & 61 & 9.30 \\
\cline { 3 - 4 } & Between 10 \& 12 h a day & 48 & 7.30 \\
\cline { 3 - 4 } & 12 h or more a day & 67 & 10.20 \\
\cline { 3 - 4 } & Preferred not to indicate & 2 & 0.30 \\
\hline
\end{tabular}


International Journal of Managing Public Sector Information and Communication Technologies (IJMPICT), Vol. 6, No. 3, September 2015

\subsection{Hypothesis test}

The path of the structural model was evaluated. Each path (Table 3) corresponds to a hypothesis. Every hypothesis was evaluated by surveying the sign, size, and statistical significance of the path coefficients among latent variables and the dependent variables. The more the path coefficient, the higher the effect of a predictor latent variable on the dependent variable. The significance of the path coefficients ( $\beta 1$ to $\beta 6$ ) was assessed by surveying the significance of the $t$ value for all path coefficients. The summary of the path results shows Table 3 . Table 3 , shows that only one out of six paths is insignificant.

The path analysis revealed that the purchase intention directly, positively, and significantly affected the actual purchase $(\beta=0.69, \mathrm{t}=6.15, \mathrm{p}<0.05)$; thus, H1 was accepted. The EWOM directly, positively, and significantly affected the trust $(\beta=0.58, \mathrm{t}=7.09, \mathrm{p}<0.05)$; thus, $\mathrm{H} 2$ is also supported. But, the results do not support hypothesis 3 where it is postulated that social identity is positively related to trust. Because the effect of social identity on trust is not significant $(\beta=0.09, \mathrm{t}=1.33, \mathrm{p}>0.05)$; thus, $\mathrm{H} 3$ was not accepted. The perceived risk directly, negatively, and significantly affected the trust $(\beta=-0.44, \mathrm{t}=-4.17, \mathrm{p}<0.05)$; thus, $\mathrm{H} 4$ was accepted. The perceived risk directly, negatively, and significantly affected the purchase intention $(\beta=-0.49, \mathrm{t}=-5.62, \mathrm{p}<0.05)$; thus, H5 was accepted. The path analysis revealed that the trust directly, positively, and significantly affected the purchase intention $(\beta=0.70, t=7.14$, $\mathrm{p}<0.05)$; thus, H6 was accepted.

Table 3: The result of research hypotheses.

\begin{tabular}{|ccccc|}
\hline Hypotheses & $\begin{array}{c}\text { Path } \\
\text { coefficient }\end{array}$ & T-statistics & $\begin{array}{c}\text { Significance } \\
\text { level }\end{array}$ & $\begin{array}{c}\text { Hypothesis test } \\
\text { results }\end{array}$ \\
\hline $\begin{array}{c}\text { purchase intention to actual } \\
\text { purchase }\end{array}$ & .69 & 6.15 & .000 & accepted \\
\hline EWOM to trust & .58 & 7.09 & .000 & accepted \\
\hline social identity to trust & .09 & 1.33 & .062 & not accepted \\
\hline perceived risk to trust & -.44 & -4.17 & .000 & accepted \\
\hline $\begin{array}{c}\text { perceived risk to purchase } \\
\text { intention }\end{array}$ & -.49 & -5.62 & .000 & accepted \\
\hline trust to purchase intention & .70 & 7.14 & .000 & accepted \\
\hline
\end{tabular}

\section{DISCUSSION}

Hypothesis 1 supports the postulated notion that purchase intention is positively related to actual purchase. The results are similar to Kim et al. (2008) where the underlying assumption postulates that a customer's intention to perform(or not) a behavior is an vital determinant of the subsequent actual behavior. Hypothesis 2 supports the claim that EWOM is positive related to trust in online shops. In other words, the results show that people generally trust EWOM communications in online shops. This earlier finding concurs with previous researches from Hennig-Thurau and Walsh (2004). The evidence suggests that people seeks risk reduction by consuming EWOM communications. In addition, consumers respond to post-purchase dissonance by generating negative EWOM. The results do not support hypothesis 3 where it is postulated that social identity is positively related to trust. To explain for such results, there could be a possibility that the survey questions are addressed to incorrect respondents. As the empirical findings show that more of the respondents did not buy any products before, this may indicate significant level of mistrust which are already exist, hence leading to such discrepancy. Another suitable description for this results can be attributed to the basic structure of the online shops sites in general. As mentioned by Boyd and Ellison (2008), online shops sites are organized around individuals and 
International Journal of Managing Public Sector Information and Communication Technologies (IJMPICT), Vol. 6, No. 3, September 2015

not community interests. Hypothesis 4 is supported, which states that perceived risk negatively affects trust. In other words, it is statistically significant that consumers' level of trust negatively related to the level of perceived risk. This finding is in line with past researches (Kim et al., 2008 and Pavlou 2003), which has significant implications for marketers. Essentially, businesses should build trust through the various interactions with customers. Trust develops loyalty and healthy relationships with customers which in turn translate into more sales. Therefore, for online retailers, they should continually deliver their marketing efforts in building trust and loyalty with their customers. This can be through enhancing transaction security, timely delivery of products and services, constant updates of events and offers etc. For hypothesis 5, the results support the postulated notion that perceived risk negatively affects intention to purchase. The empirical findings do validate the Theory of Planned Behavior (Ajzen, 2005) where attitude towards behavior (i.e. perceived risk) affects intention. In support of hypothesis 6 , trust is found to be significantly influencing intention to purchase. This finding is in line with past studies (Jones and Kim, 2010; Ha and Perks, 2005). The results shows that the respondents do generally believe that the online retailers and community are trustworthy, which reiterates the importance of trust to entice consumers to patronize. For marketers, trust building has to be of utmost consideration in managing relationships and communications with consumers. As discussed earlier, marketers need to recognize the importance for managing WOM communications to ensure the essential level of trust between consumers and businesses exists.

\section{REFERENCES}

[1] Ajzen, Icek (2005), “Attitudes, Personalities and Behavior, (2nd Edition)” McGraw Hill Education.

[2] Boyd, Danah M. and Nicole B. Ellison (2008), "Social Network Sites: Definition, History, and Scholarship", Journal of Computer-Mediated Communication 13, pp. 210-230.

[3] Brown, Jo., Amanda J. Broderick and Nick Lee (2007), "Word of Mouth Communications Within Online Communities: Conceptualizing the Online Social Network", Journal of Interactive Marketing, Volume 21, Number 3, Summer.

[4] Davis, F.D. (1986), "A technology acceptance model for empirically testing new end-user information systems: theory and results", doctoral dissertation, MIT Sloan School of Management, Cambridge, MA.

[5] Evans, Dave and Bratton, Susan (2010), "Social Media Marketing: An Hour a Day." John Wiley \& Sons.

[6] Frings, Daniel and Albery, Ian P. (2015), The Social Identity Model of Cessation Maintenance: Formulation and initial evidence, Addictive Behaviors 44, p 36.

[7] Goyette Isabelle, Line Ricard, Jasmin Bergeron, François Marticotte (2010), "E-WOM Scale: Word-of-Mouth Measurement Scale for e-Services Context", Canadian Journal of Administrative Sciences, 27(1), pp. 5-23.

[8] Ho, Hong-Fa (2014), The effects of controlling visual attention to handbags for women in online shops: Evidence from eye movements, Computers in Human Behavior 30, p 146.

[9] Hennig-Thurau Thorsten, Malthouse, Edward C., Friege Christian, Gensler Sonja, Lobschat Lara, Rangaswamy Arvind and Skiera Bernd (2010), "The Impact of New Media on Customer Relation.” Journal of Service Research, 13, p.311.

[10] Hansen, Torben (2005), "Perspectives on consumer decision making: An integrated approach.” Journal of Consumer Behavior , Vol. 4, 6, pp. 420-437.

[11] Kim, Eunice., Yongjun, Sung., Hamsu, Kang(2014), Brand followers' retweeting behavior on Twitter: How brand relationships influence brand electronic word-of-mouth, Computers in Human Behavior 37, p.19.

[12] Kozinets Robert V., De Valck Kristine, Wojnicki Andrea C., \& Wilner Sarah J.S. (2010), "Networked Narratives: Understanding Word-of-Mouth Marketing in Online Communities," Journal of Marketing Vol. 74 (March), pp. 71-89.

[13] Kim Dan J., Donald L. Ferrin and H. Raghav Rao (2008), “A trust-based consumer decision making model in electronic commerce: The role of trust, perceived risk, and their antecedents", Decision Support Systems 44, pp. 544-564. 
[14] Loh, Aizhen (2011), A Study on Influence of Trust, Social identity, Perceived Risk and EWOM on Consumer Decision-Making Process in the context of Social Network Sites, Master's Thesis in Business Administration, MBA program, Blekinge Tekniska.

[15] Lin, Chieh-Peng (2010) "Learning Virtual Community Loyalty Behavior From a Perspective of Social Cognitive Theory", International Journal of Human-Computer Interaction, 26: 4, pp.345- 360.

[16] Martins, Carolina., Oliveira, Tiago., Popovic, Ales (2014), Understanding the Internet banking adoption: A unified theory of acceptance and use of technology and perceived risk application, International Journal of Information Management 34, p3.

[17] Pavlou, Paul A. (2003), “Consumer Acceptance of Electronic Commerce: Integrating Trust and Risk with the Technology Acceptance Model", International Journal of Electronic Commerce, Spring2003, Vol. 7, Issue 3, pp. 101-134.

[18] Quinton, Sarah and Sally Harridge-March (2010), "Relationships in online communities: the potential for marketers", Journal of Research in Interactive Marketing Vol. 4, No. 1, pp. 59-73.

[19] Rauniar, Rupak., Greg, Rawski., Jei, Yang., Ben, Johnson (2014), "Technology acceptance model (TAM) and social media usage: an empirical study on Facebook", Journal of Enterprise Information Management, Vol. 27, Iss 1 pp. 6-30.

[20] Steffes, Erin M. and Lawrence E. Burgee (2008), "Social Ties and Online Word-of-Mouth", Internet Research, Vol. 19, No. 1, pp. 42-59

[21] Teo, Thompson S.H. and Yon Ding Yeong (2003), "Assessing the consumer decision process in the digital marketplace", Omega 31, pp. 349 - 363.

[22] Wasko M. McLure and Faraj S. (2000), "It is what one does": why people participate and help others in electronic communities", Journal of Strategic Information Systems, pp. 155-173

[23] Yoon, Hyun Shik., Occena, Luis G. (2015), Influencing factors of trust in consumer-toconsumer electronic commerce with gender and age, International Journal of Information Management 35, p 353.

[24] Zeng Fue, Huang Li, Dou Wenyu (2009), "Social Factors in User Perceptions And Responses To Advertising In online Social Networking Communities," Journal of Interactive Advertising, Vol 10, No1 (Fall), pp.1-13 